\title{
Life events and donor lapse among blood donors in Denmark
}

Tjeerd W. Piersma, ${ }^{1-4}$ Eva-Maria Merz, ${ }^{1,3}$ René Bekkers, ${ }^{2,3}$ Wim de Kort, ${ }^{1,5}$ Steffen Andersen, ${ }^{6}$ Henrik Hjalgrim, ${ }^{7}$ Klaus Rostgaard, ${ }^{7}$ Kaspar René Nielsen, ${ }^{8}$ Henrik Ullum ${ }^{4}$

\footnotetext{
${ }^{1}$ Department of Donor Medicine Research, Sanquin Research, Amsterdam, the Netherlands

${ }^{2}$ Center for Philanthropic Studies, Vrije Universiteit, Amsterdam, the Netherlands

${ }^{3}$ Department of Sociology, Vrije Universiteit, Amsterdam, the Netherlands

${ }^{4}$ Department of Clinical Immunology, Copenhagen University Hospital, Rigshospitalet, Copenhagen, Denmark

${ }^{5}$ Department of Social Medicine, Academic Medical Center, Amsterdam, the Netherlands

${ }^{6}$ Department of Finance, Copenhagen Business School, Frederiksberg, Denmark

${ }^{7}$ Department of Epidemiology Research, Statens Serum Institut, Copenhagen, Denmark

${ }^{8}$ Department of Clinical Immunology, Aalborg University Hospital, Aalborg, Denmark
}

\section{Running head}

Life events and donor lapse in Denmark 


\begin{abstract}

\section{Background}

The likelihood of donating blood changes over the life course, with life events shown to influence entry to and exit from the donor population. While these previous findings provide valuable insights for donor management, blood collection agencies need to be cautious about generalizing findings to other countries as blood donor behaviour is context-specific. To examine cross-country variations in donor behaviour, the repeatability of a previous Dutch study on life events and blood donor lapse is examined by using a sample of Danish donors.
\end{abstract}

\title{
Study design and methods
}

Register data from Statistics Denmark was linked to the Scandinavian Donations and Transfusions database $(n=152,887)$. Logistic regressions were conducted to examine the association between life events in 2009-2012 and blood donor lapse in 2013-2014.

\section{Results}

Of the total sample, 69,079 (45.2\%) donors lapsed. Childbirth and losing a job increased the lapsing risk by $11 \%$ and $16 \%$, respectively, while health-related events in the family (i.e., blood transfusion, disease and death) decreased the lapsing risk by $5 \%, 7 \%$ and $9 \%$, respectively.

\section{Conclusion}

Life events are associated with donor lapse of Danish donors. These results are comparable to previous findings from the Netherlands (i.e., childbirth and labor market transitions increased lapsing risk; health-related events decreased lapsing risk), with two thirds of the associations being in the same direction. Differences between study results were mainly related to effect sizes and demographic compositions of the donor pools. We argue contextual factors to be of importance in blood donor studies.

\section{Key words}

Blood donors, life events, donor lapse, replication, register data 


\section{INTRODUCTION}

Why and when do people give blood? Life events related to family composition, health of family and friends, and labour market transitions affect blood donor behaviour over the life course. ${ }^{1,2}$ Longitudinal studies from Germany and the Netherlands showed such life events to impact both entry to and exit from the donor pool, hereby illustrating the importance of longitudinal data to examine behavioural change across the blood donor career.

Regarding entry to the donor pool, German data showed that people who recently divorced or finished their education were more likely to start donating blood, while people who got a child or experienced the death of a parent were less likely to start a donor career. ${ }^{1}$ Regarding exit from the donor pool, Dutch data showed that childbirth, getting a job and losing a job increased the likelihood of donor lapse, while a blood transfusion for someone close and the death of a loved one decreased this likelihood. ${ }^{2}$

Blood donor studies based on self-reports indicated that barriers such as time constraints and decreased social connections are possible reasons to stop donating blood after experiencing a life event. ${ }^{3}$ Individuals with more available time, and more human and social capital (e.g., available health and social connections) were indeed more likely to donate blood, ${ }^{4}$ and these mechanisms were found to partially explain the association between life events and donor lapse among Dutch donors. ${ }^{2}$

While these findings provide valuable insights for donor recruitment and retention, blood collection agencies (BCAs) need to be cautious in generalizing these findings to other countries. Blood donation and its antecedents are shown to be context-specific, with contextual factors such as collection practices and cultural differences influencing blood donor attitudes and behaviour. ${ }^{5,6}$ For instance, organizational variation between European BCAs has been shown to be related to donor diversity and loyalty. ${ }^{7}$ State-run BCAs recruit more male donors of higher socioeconomic status who are likely to donate only once or twice, while BCAs under a Red Cross regime attract fewer but more loyal donors who are more equally distributed across socioeconomic groups. ${ }^{7}$

To contribute to these country studies and identify more universal and possible context-specific mechanisms for blood donor behavior, we compared the association between life events and blood donor lapse between Denmark and the Netherlands by testing the repeatability ${ }^{8}$ of previous findings ${ }^{2}$ among a large sample of Danish donors. Moreover, by using register data from Statistics Denmark (SD), ${ }^{9}$ linked to the Scandinavian Donations and Transfusions (SCANDAT) database, ${ }^{10}$ were able to provide more accurate estimates of true effect sizes compared to findings from the Dutch survey study, e.g., by eliminating the possibility of false-positive self-reports as a result of recall bias.

\section{MATERIALS AND METHODS}

In order to test the repeatability of previous findings, we selected data, procedures, measures and statistical analyses based on methodological decisions from the previous study (Appendix A and https://osf.io/9chtq/).

\section{Data and procedure}

$\mathrm{SD}^{9}$ and SCANDAT ${ }^{10}$ were used to examine the association between life events and blood donor lapse among Danish donors. SD contains a wide array of information on the Danish population, ranging from societal information on geography, environment and energy to individual information on labour, income and wealth. SCANDAT contains data on all Danish blood donors and recipients who have been 
registered since the start of the computerized blood bank system in 1981 and has been used to study a variety of topics concerning blood donor behaviour and transfusion medicine because of the possibility to link SCANDAT to SD using Civil Registration Numbers (CRNs) as personal identifiers. ${ }^{10,11}$ According to Danish law, register-based research does not require ethical approval. ${ }^{12}$ For this study we used CRNs to link SCANDAT to subsets of SD to examine if active blood donors - who made at least one donation in 2008 - experienced a life event in 2009-2012 (i.e., health-related event in the family, childbirth, losing a job, starting a job), and if these donors lapsed in 2013-2014.

From the sample of active donors, those who where ineligible for future blood donations as a result of various medical (i.e., death, permanent deferral) and non-medical reasons (i.e., migration, reaching the upper age limit of 67 ), were excluded from the sample. To retrieve this information we used the ineligibility criteria list from the Danish blood bank ${ }^{13}$ and checked whether any of these criteria applied to the donor using migration, death and hospitalization records from SD. Our final sample consisted of 152,887 blood donors.

\section{Measures}

Blood donor lapse. Blood donor lapse was defined as not making a donation for 24 consecutive months, ${ }^{14}$ with individual donation information retrieved from SCANDAT $(0=$ no donor lapse, $1=$ donor lapse).

Life events. Information on the occurrence of health-related events among family members was retrieved from SCANDAT (i.e., blood transfusion) and SD (i.e., serious disease, death). Based on CRNs we matched the donor to parents, children and siblings and then matched these family members to transfusion, hospitalization and death records. Using this information we created a time-dependent dichotomous variable representing whether the donor experienced a health-related event in the family (e.g., $0=$ no family member died, $1=$ family member died). Information on childbirth was extracted from SD by matching newborn children to their parents using CRNs. We transformed this data such that the individual record of the donor included the CRN of their newborn child and recoded this as a time-dependent dichotomous variable representing whether a child was born to the donor ( 0 = no childbirth, 1 = childbirth). Information on donors losing or starting a job was retrieved from SD. Time-dependent dichotomous variables were created by tracking changes in employment status: from having a paid job to unemployment ( $0=$ stayed at their job, $1=$ lost their job), and from unemployment to having a paid job ( $0=$ remained unemployed, $1=$ started a job).

Mechanisms. To further explore the association between life events and donor lapse we included two possible mediating mechanisms in the models. The total number of weekly working hours was included as a proxy for the available time to donate, with a higher number of weekly working hours representing higher costs to donate blood as time becomes a scarcer resource when working hours increase. Having other blood donors in the family was included as a proxy for the influence of social networks. Based on CRNs we matched the donors to their parents, children, siblings and spouse, and then matched the CRNs of these family members to SCANDAT to create a dichotomous variable representing whether the donor knew donors in the family $(0=$ does not know other donors, $1=$ knows other donors).

Control variables. Sex, age, educational leve and total number of previous blood donations were added to the model as control variables. Educational level was coded as lower, medium and higher education according to the International Standard Classification of Education (ISCED) 2011, ${ }^{15}$ a comprehensive framework to categorize educational levels and facilitate cross-country comparisons of educational systems. 


\section{Statistical analyses}

Analyses were conducted using Stata 15 (College Station, TX: StataCorp LLC). Conducting logistic regression analyses we estimated the association between life events and donor lapse. Donor inclusion requirements included having been 'at risk' for experiencing a life event of interest, i.e., women aged $\leq 45$ and men aged $\leq 55$ for childbirth $(n=117,266)$, unemployed donors for starting a job $(n=7,570)$, employed donors for losing a job $(n=129,836)$, and all donors for the health-related events $(n=$ $152,887)$. We then obtained predicted probabilities for donors who were at risk for the event and did or did not experience the event, keeping the other variables in the model at their means.

As to examine whether childbirth differently affected donor lapse for men and women we added an interaction term to the model. Mediation analyses (i.e., $Z_{\text {Mediation }}{ }^{16}$ were performed as to test to what extent the costs of donating blood (i.e., increased working hours) and influences from the social network (i.e., knowing other blood donors) were able to explain the association between life events and donor lapse, only when this association proved to be statistically significant.

\section{RESULTS}

\section{Life events and the Danish donor population}

Of the total donor sample, $45.2 \%(n=69,079)$ lapsed in 2013-2014. Life events occuring most often to the donors were a serious disease in a family member $(22.7 \%, n=34,756)$, childbirth $(15.1 \%, n=$ $23,056)$, and a blood transfusion for a family member $(9.3 \%, n=14,165)$. Table 1 shows descriptive statistics of all study measures. Compared to the Dutch donor sample (Appendix B) the Danish donor sample had a lower mean age (39.7 vs. 46.7), comprised of more male donors ( $53.1 \%$ vs. $47.2 \%$ ), and had a lower average number of previous donations (11 vs. 21). Most notably, the number of lapsed donors was higher in Denmark than in the Netherlands ( $45.2 \%$ vs. $25.3 \%)$. With regard to the occurrence of health-related life events we noticed some proportional differences between the samples. A serious disease in a family member and the death of a family member were reported by $40.5 \%$ and $18.9 \%$ of the Dutch donors, and only by $22.7 \%$ and $8.8 \%$ of the Danish donors, respectively.

\section{Health of family members}

Blood transfusion. Donors experiencing a blood transfusion for a family member were $5 \%$ less likely to lapse than donors who did not experience such an event $(\mathrm{OR}(95 \% \mathrm{Cl})=0.91(0.88-0.94), p<.001)$. We found no evidence of a mediating role of knowing other blood donors in the association between a blood transfusion and donor lapse. These results are comparable to earlier findings in the Netherlands, with Dutch donors experiencing a blood transfusion being $11 \%$ less likely to lapse.

Serious disease. Donors experiencing a serious disease in the family were $7 \%$ less likely to lapse than donors who did not experience a serious disease in the family $(\mathrm{OR}(95 \% \mathrm{Cl})=0.88(0.86-0.90), p$ $<.001)$. Subsequent mediation analysis showed no evidence of knowing other donors as an explaining mechanisms for the association between a serious disease and donor lapse. These results were different from previous findings, where no significant difference was found among Dutch donors in their lapsing risk after a serious disease in the family.

Death. Donors having lost one of their family members were $9 \%$ less likely to lapse than donors who did not experience a family member's death $(\mathrm{OR}(95 \% \mathrm{Cl})=0.84(0.81-0.87), p<.001)$. As was the case in the other health-related events, further analysis revealed no evidence of knowing other donors being a mediating factor. The association between a family member's death and donor lapse is comparable to the one found among Dutch donors (i.e., an $8 \%$ increase in lapsing risk). 


\section{Interrelationship between transfusion, disease and death}

Since health-related events were correlated to each other (Appendix C), we explored their interrelationship in the negative association with blood donor lapse. Table 3 shows how the unstandardized coefficients changed when the health-related events were introduced in a stepwise manner. While the coefficients for a blood transfusion halved after adding serious disease or a family member's death to the model, the coefficients of the latter two changed only slightly compared to their separate association with donor lapse. The association between a blood transfusion and lapse therefore seems to be subordinate to the association for a serious disease or death. When all three health-related events were added to the model (Model 7), the association between a blood transfusion and lapse disappeared, while the coefficients for serious disease and death only slightly decreased. In this full model, death showed the strongest negative association with donor lapse, while serious disease showed the most robust association across the combined models.

\section{Childbirth}

Donors who got a child were $11 \%$ more likely to lapse than donors who did not get a child within the same period $(\mathrm{OR}(95 \% \mathrm{Cl})=1.21(1.18-1.25), p<.001)$. While childbirth increased the lapsing risk for both men $(\mathrm{OR}(95 \% \mathrm{Cl})=1.18(1.13-1.23), p<.001)$ and women $(\mathrm{OR}(95 \% \mathrm{Cl})=1.24(1.18-1.29), p<$ $.001)$, this association was significantly stronger for women than men. Compared to the study from the Netherlands, effect sizes differ considerably with Dutch donors who got a child being $56 \%$ more likely to lapse than donors who did not get a child. Moreover, in the Netherlands no significant difference was found between men and women in their lapsing risk after childbirth.

\section{Labour market transitions}

Starting a job. No difference was found between donors who started a job and donors who stayed unemployed in their subsequent lapsing risk. These results differ quite strongly from earlier results in the Netherlands. Starting a job was positively associated with lapse among Dutch donors, with donors who started a job being $22 \%$ more likely to lapse compared with donors who stayed unemployed.

Losing a job. Donors who lost their job were $16 \%$ more likely to lapse than donors who stayed at their job during the same period $(\mathrm{OR}(95 \% \mathrm{Cl})=1.32(1.25-1.39), p<.001)$. Mediation analysis showed that knowing fewer other blood donors was a significant mediator in the model, yet explaining only $3 \%$ of the variance in the relation between losing a job and donor lapse $(z=5.36, p<.001)$. These results replicate previous results from the Netherlands, but effect sizes differ slightly as Dutch donors were $35 \%$ more likely to lapse after losing their job, while the same effect was found for the small mediating role of knowing other donors in explaining the association between losing a job and donor lapse.

\section{DISCUSSION}

\section{Life events and donor lapse in Denmark}

Using longitudinal data from SCANDAT and SD, we conclude that life events related to childbirth and work status, as well as health-related events in the family, are associated with blood donor lapse. Childbirth and losing a job increased the risk of donor lapse, with childbirth being more detrimental for future blood donations of women than men. In contrast, health-related events in the family 
decreased the risk of donor lapse. Once more, the likelihood to donate blood was shown to vary across the donor career, thus illustrating the dynamic nature of blood donor behaviour.

For a large part these results are in line with previous findings from cross-sectional blood donor studies based on self-reports. Time constraints due to childbirth and family responsibilities appear to be among the main reasons for donors to discontinue donating blood, ${ }^{3}$ while health-related events in the family were mentioned being a motivational factor to start donating blood ${ }^{17}$ as well as a reason to continue donating over time. ${ }^{18}$ Our finding that people are more likely to lapse after losing their job alignes with previous research suggesting that social connections with co-workers influence donation decisions. ${ }^{17}$

We also found some descrepancies compared with previous studies. Time constraints due to work are a common self-reported reason for donors to stop donating blood, ${ }^{19}$ but we found no statistically significant association between starting a job and donor lapse. Also, we found no evidence for social connections explaining the association between health-related events and donor lapse. Further understanding of underlying motivational mechanisms is important to provide insight in preventing donors from lapse at certain life stages.

\section{Country comparisons between Denmark and the Netherlands}

We found the associations to be comparable between Denmark and the Netherlands. Of the events studied here, two thirds showed the same associative directions with donor lapse, while none of them showed opposite directions. Moreover, half of all confidence intervals showed an overlap between the studies. One might assume that certain (motivational) mechanisms are universal factors associated with blood donor behaviour across the donor career. Childbirth constraints a person's available time, ${ }^{20}$ losing a job decreases self-perceived health, ${ }^{21}$ and health-related events in the family might raise feelings of moral responsibility, regardless of the local blood collection regime or other contextual differences between countries.

However, we also found some differences between the study results, mainly related to donor sample compositions and the magnitude of effect sizes. Regarding contextual differences between Denmark and the Netherlands, donor samples might differ as a result of organizational variation in blood collection regimes. Following Healy's categorization, ${ }^{7}$ blood collection in the Netherlands originates from a Red Cross regime which is rooted in voluntary, religious organizations, therefore being more likely to attract fewer but more loyal donors. The Danish collection regime might be more effective in recruiting new, young donors but less so in retaining them over time. This could explain why the Danish sample shows a higher proportion of younger, lapsed donors with a lower number of previous donations. Moreover, differences might be explained by BCA recruitment strategies. In the Netherlands, recruitment was shown to be related to donor diversity and loyalty. ${ }^{22}$ Differences between Danish and Dutch recruitment and retention strategies might therefore lead to different donor pools in terms of diversity and loyalty, subsequently influencing the extent to which life events impact on donor lapse.

Contextual differences other than those exerted by BCAs might contribute to differences in effect sizes. For instance, regulations regarding parental care after childbirth differ significantly between countries. In the Netherlands, fathers have only two days off after childbirth, ${ }^{23}$ posing serious constraints on their available time, subsequently increasing their lapsing risk. ${ }^{2}$ The association between childbirth and lapse is smaller for Danish donors, possibly explained by extended parental leave providing parents, especially fathers, with more time after childbirth. ${ }^{24}$ Yet, the list of explanatory contextual factors is inconclusive. For instance, starting a job showed a strong positive association with 
donor lapse in the Netherlands, but not in Denmark. We speculated that differences might be the result of country variations in commuting distances, importance of the work-life balance or blood collection drives at businesses, but no such differences were found ${ }^{25-28}$. Are there contextual factors at play here, or are the different result the mere effect of data differences?

Regarding data differences, donor samples and effect sizes could differ as a result of the sole use of register data in the current study as opposed to the combination of register and survey data in the study from the Netherlands. The current study includes all active donors, while the previous study only included donors participating in both waves of the survey. Analyses showed non-responders being more likely younger, male, lapsed donors having made a lower number of average donations, possibly explaining why the Danish sample shows a higher proportion of donors with these characteristics. Moreover, register data eliminates the possibility of introducing recall bias and the telescoping effect. ${ }^{29}$ In studying self-reporting on the occurrence of life events in surveys, respondents more likely recall life events closely related to their donation decision (i.e., recall bias), or wrongly assign the occurrence of a life event to a specific time-frame when this time-frame is introduced (i.e., telescoping effect), hereby overestimating effect sizes. Register data does not include false negatives, therefore being more accurate in estimating the true effect sizes.

\section{Strengths and limitations}

Although this study provides valuable insights on cross-country variations in blood donor behaviour, providing more accurate and reliable estimations, our study also has some limitations. Registries typically provide more accurate and complete sources of data, but do not include relevant variables related to subjective perceptions and other individual factors such as the perceived difficulty to plan a donation and talking to other donors. Instead, we used variables serving as proxies for these missing variables, corresponding to other mediators from the Dutch theoretical framework: weekly working hours and the extent to which donors know other blood donors. In this way we have used the data without introducing too many incongruences.

While using different contexts and data in replication studies it is difficult to pinpoint exactly which differences explain inconsistencies between study results. We acknowledge this limitation. Our aim was to examine the association between life events and donor behavior in Denmark. The comparison with the Netherlands shows that contextual and data difference could yield various study outcomes. Researchers as well as BCAs need to be aware of such differences and its implications in interpreting international study results.

\section{Future theoretical and practical directions}

The influence of life events on blood donor behavior across the life course so far has been studied in three different countries: the Netherlands, Germany and Denmark. While certainly there are differences between these countries, they also are quite comparable with respect to collection systems as well as socio-economic circumstances and cultural orientation. ${ }^{25,26,30,31}$ It is worthwhile to further examine cross-country differences in a broader variety of countries, including the United States, the UK, Canada and Australia, as to allow for conclusions on the role of contextual factors in donor behavior across the donor career.

We suggest future studies to focus on underlying mechanisms explaining the relation between life events and donor behavior. While the current study and the study from the Netherlands showed social and practical concerns to partially explain why life events impact on donor lapse, the bulk of these associations is still unaccounted for. For instance, neither of the two studies found evidence for 
social mechanisms playing a role in the relation between health-related events and donor lapse, nor could we conclude on the different results for starting a job and donor lapse.

In-depth studies of these associations would be of practical interest in making evidence-based decisions on the development of targeted donor recruitment and retention strategies. For instance, exploring work-home-donation distances might increase understanding in why people change their donation decision after starting or losing a job, and assist BCAs in deciding on where and when to open their donation locations. Moreover, strategically positioning of collection sites might be effective in recruiting underrepresented groups of young, male and ethnically diverse donors, which is essential in maintaining a sufficient and matching blood supply. ${ }^{32}$ At the same time, BCAs need to be careful in implementing international practices to their own donor management policies, since we showed that blood donors and their behaviour may differ between countries. 


\section{CONTRIBUTIONS}

TP, EM, RB, WK and HU contributed to the study design. TP developed the main conceptual ideas and wrote the manuscript with support from all other authors. TP wrote the code and performed the statistical analyses, based on previous work from SA and with additional analyses by Andreas Stribolt Rigas (Copenhagen University Hospital, Rigshospitalet). All authors provided critical feedback on the interpretation of the outcomes and the final version of the manuscript. 


\section{REFERENCES}

1. Soliman M, Boenigk S, Studte S. Improving blood donation management by considering individual life events - new insights from the German socio-economic panel in progress.

2. Piersma TW, Bekkers R, de Kort WLAM, et al. Blood donation across the life course: the influence of life events on donor lapse. Journal of Health and Social Behavior accepted for publication.

3. Piersma TW, Bekkers R, Klinkenberg EF, et al. Individual, contextual and network characteristics of blood donors and non-donors: a systematic review of recent literature. Blood Transfusion 2017;15:382-97.

4. Bekkers R. Traditional and health-related philanthropy: the role of resources and personality. Social Psychology Quarterly 2006;69:349-66.

5. Merz E-M, Zijlstra BJH, De Kort WLAM. Perceived blood transfusion safety: a cross-European comparison. Vox Sanguinis 2016;110:258-65.

6. De Kort WLAM, Wagenmans ET, Van Dongen A, et al. Blood product collection and supply: a matter of money? Vox Sanguinis 2010;98:e201-e8.

7. Healy KJ. Embedded altruism: blood collection regimes and the European Union's donor population. American Journal of Sociology 2000;105:1633-57.

8. Freese J, Peterson D. Replication in social science. Annual Review of Sociology 2017;43:14765.

9. DST. Statistics Denmark; 2018. Available from: https://www.dst.dk/en. Last accessed: 30-102018

10. Edgren G, Rostgaard K, Vasan SK, et al. The new Scandinavian Donations and Transfusions database (SCANDAT2): a blood safety resource with added versatility. Transfusion 2015;55:1600-6.

11. Edgren $\mathrm{G}, \mathrm{Hjalgrim} \mathrm{H}$, Tran TN, et al. A population-based binational register for monitoring long-term outcome and possible disease concordance among blood donors and recipients. Vox Sanguinis 2006;91:316-23.

12. SD. The Danish system for access to micro data: Statistics Denmark; 2014. Available from: https://www.dst.dk/ext/645846915/0/forskning/Access-to-micro-data-at-StatisticsDenmark_2014--pdf. Last accessed: 19-2-2019

13. Blodbanken. Karantæneregler [Quarantine regulations]: Blodbanken; 2018. Available from: https://bloddonor.dk/tapning-hvor-og-hvordan/karantaeneregler/. Last accessed: 9-11-2018

14. De Kort WLAM, Veldhuizen IJT. DOMAINE. Donor management manual. Nijmegen, The Netherlands: Sanquin Bloedvoorziening, 2010.

15. UNESCO. International Standard Classification of Education (ISCED) 2011. Montreal, Canada: UNESCO Institute for Statistics; 2012.

16. lacobucci D. Mediation analysis and categorical variables: the final frontier. Journal of Consumer Psychology 2012;22:582-94.

17. Charbonneau J, Cloutier M-S, Carrier É. Whole blood and apheresis donors in Quebec, Canada: demographic differences and motivations to donate. Transfusion and Apheresis Science 2015;53:320-8.

18. Bani M, Strepparava MG. Motivation of Italian whole blood donors and the role of commitment. Psychology, Health \& Medicine 2011;16:641-9.

19. Klinkenberg EF, Romeijn B, De Kort WLAM, et al. Reasons to end the donor career: a 
quantitative study among stopped donors in the Netherlands. Transfusion Medicine 2018;28:200-7.

20. Schmitz H. Why are the unemployed in worse health? The causal effect of unemployment on health. Labour Economics 2011;18:71-8.

21. Elder L, Greene S. The politics of parenthood: causes and consequences of the politicization of the American families. Albany, NY: State University of New York Press, 2012.

22. Piersma TW, Klinkenberg EF. The relation between blood donor recruitment and donor diversity and loyalty in the Netherlands. ISBT Science Series 2018;13:384-93.

23. Rijksoverheid. Geboorteverlof voor partners [Parental leave for partner]: Rijksoverheid; 2019. Available from: https://www.uwv.nl/werkgevers/werknemer-krijgtkind/zwanger/werknemer-is-zwanger-wazo/detail/verlofperiode-zwangerschap. Last accessed: 29-1-2019

24. Øresunddirekt. Parental leave when working in Denmark: Øresunddirekt; 2018. Available from: https://www.oresunddirekt.se/in-english/in-english/family-parenting-indenmark/parental-leave-when-you-work-in-denmark. Last accessed: 29-1-2019

25. OECD. OECD Better Life Index: the Netherlands: Organisation for Economic Co-operation and Development (OECD); 2018. Available from: http://www.oecdbetterlifeindex.org/countries/netherlands/. Last accessed: 24-1-2019

26. OECD. OECD Better Life Index: Denmark: Organisation for Economic Co-operation and Development (OECD); 2018. Available from: http://www.oecdbetterlifeindex.org/countries/denmark/. Last accessed: 24-1-2019

27. CBS. Bijna 4 op de 10 werkt en woont in dezelfde gemeente [Almost 4 out of 10 lives and works in the same municipality]: Centraal Bureau voor de Statistiek (CBS); 2017. Available from: https://www.cbs.nl/nl-nl/nieuws/2017/32/bijna-4-op-de-10-werkt-en-woont-indezelfde-gemeente. Last accessed: 24-1-2019

28. DI. Stor forskel i pendlingsafstand på tværs af køn, alder og kommuner [Big difference in commuting distance across sex, age groups and municipalities]: Dansk Industri (DI); 2018. Available from: http://publikationer.di.dk/dikataloger/857/. Last accessed: 24-1-2019

29. Bekkers R, Wiepking P. Accuracy of self-reports on donations to charitable organizations. Quality \& Quantity 2011;45:1369-83.

30. Insights H. Country comparison: Hofstede Insights; 2018. Available from: https://www.hofstede-insights.com/country-comparison/

31. OECD. OECD Better Life Index: Germany: Organisation for Economic Co-operation and Development (OECD); 2018. Available from: http://www.oecdbetterlifeindex.org/countries/germany/. Last accessed: 31-1-2019

32. Anani W, Denomme G. Data visualization of a large genotyped donor database. Vox Sanguinis 2018;113. 


\section{TABLES}

Table 1. Descriptive statistics of study measures, for total sample and stratified by donor status*

\begin{tabular}{|c|c|c|c|}
\hline Characteristic & $\begin{array}{r}\text { All donors } \\
(n=152,887)\end{array}$ & $\begin{array}{r}\text { Active donors } \\
(\mathrm{n}=83,808 ; 54.8 \%)\end{array}$ & $\begin{array}{r}\text { Lapsed donors } \\
(n=69,079 ; 45.2 \%)\end{array}$ \\
\hline \multicolumn{4}{|l|}{ Life events } \\
\hline Transfusion & 14,165 (9.3\%) & $8,141(9.7 \%)$ & $6,024(8.7 \%)$ \\
\hline Serious disease & $34,756(22.7 \%)$ & $20,076(24.0 \%)$ & $14,680(21.3 \%)$ \\
\hline Death & $13,381(8.8 \%)$ & 7,955 (9.5\%) & $5,426(7.9 \%)$ \\
\hline Childbirth & $23,056(15.1 \%)$ & $11,584(13.8 \%)$ & $11,472(16.6 \%)$ \\
\hline Starting a job & $5,378(3.5 \%)$ & $2,466(1.2 \%)$ & $2,912(4.2 \%)$ \\
\hline Losing a job & $6,203(4.1 \%)$ & $2,881(3.4 \%)$ & $3,322(4.8 \%)$ \\
\hline \multicolumn{4}{|l|}{ Costs } \\
\hline Working hours & $22.6( \pm 8.23)$ & $23.1( \pm 7.75)$ & $21.8( \pm 8.76)$ \\
\hline \multicolumn{4}{|l|}{ Social network } \\
\hline Know other donors & $40,067(26.2 \%)$ & $24,491(29.2 \%)$ & $15,576(22.6 \%)$ \\
\hline Age & $39.7( \pm 12.30)$ & $40.7( \pm 11.41)$ & $38.1( \pm 13.28)$ \\
\hline \multicolumn{4}{|l|}{ Sex } \\
\hline Male & $81,131(53.1 \%)$ & $47,126(56.2 \%)$ & 34,005 (49.2\%) \\
\hline Female & $71,756(46.9 \%)$ & $36,682(43.8 \%)$ & $35,074(50.8 \%)$ \\
\hline \multicolumn{4}{|l|}{ Educational level } \\
\hline Low & $21,732(14.2 \%)$ & 10,969 (13.9\%) & $10,763(15.6 \%)$ \\
\hline Middle & $87,448(57.2 \%)$ & $48,815(58.3 \%)$ & $38,633(55.9 \%)$ \\
\hline High & $38,593(25.4 \%)$ & $21,613(25.8 \%)$ & $16,980(24.6 \%)$ \\
\hline Previous blood donations & $11(5-22)$ & $13(6-24)$ & $9(4-19)$ \\
\hline
\end{tabular}


Table 2. Results for the logistic regression analyses of life events on donor lapse ${ }^{*}$, mediated by the hypothesized mechanisms ${ }^{\dagger}$

\begin{tabular}{|c|c|c|c|c|c|c|c|c|}
\hline \multirow[b]{2}{*}{ Life events \& mechanisms ${ }^{\ddagger}$} & \multicolumn{3}{|c|}{ Model A } & \multicolumn{3}{|c|}{ Model B } & \multicolumn{2}{|c|}{$Z_{\text {Mediation }}$} \\
\hline & $\mathrm{B}^{\S}$ & SE & $\mathrm{OR}^{\mathrm{II}}(95 \% \mathrm{Cl})$ & B & SE & OR $(95 \% \mathrm{Cl})$ & $\%$ mediated $^{\natural}$ & Z-value \\
\hline Transfusion & $-0.10 * * *$ & 0.02 & $0.91(0.88-0.94)$ & $-0.08 * * *$ & 0.02 & $0.91(0.88-0.94)$ & & \\
\hline Know other donors & & & & $-0.40 * * *$ & 0.01 & $0.69(0.68-0.71)$ & - & 0.05 \\
\hline Serious disease & $-0.13^{* * *}$ & 0.01 & $0.88(0.86-0.90)$ & $-0.13^{* * *}$ & 0.01 & $0.88(0.62-0.90)$ & & \\
\hline Know other donors & & & & $-0.37 * * *$ & 0.01 & $0.69(0.67-0.71)$ & - & 0.01 \\
\hline Death & $-0.17 * * *$ & 0.02 & $0.84(0.81-0.87)$ & $-0.17 * * *$ & 0.02 & $0.84(0.81-0.87)$ & & \\
\hline Know other donors & & & & $-0.37 * * *$ & 0.01 & $0.69(0.68-0.71)$ & - & 1.32 \\
\hline Childbirth & $0.19 * * *$ & 0.02 & $1.21(1.18-1.25)$ & - & - & - & - & - \\
\hline Start job & -0.02 & 0.05 & $0.98(0.88-1.10)$ & - & - & - & - & - \\
\hline Lose job & $0.28 * * *$ & 0.03 & $1.32(1.25-1.39)$ & $0.27 * * *$ & 0.03 & $1.31(1.24-1.38)$ & & \\
\hline Know other donors & & & & $-0.36 * *$ & 0.01 & $0.70(0.68-0.72)$ & $3 \%$ & $5.36^{* * *}$ \\
\hline
\end{tabular}

${ }^{*}$ Blood donor lapse for non-medical reasons. ${ }^{\dagger}$ Effects are estimated separately for each life event and its hypothesized mechanisms, and only when the donor is at risk for experiencing the life event: transfusion, disease and death $(n=152,887)$, childbirth $(n=117,266)$, start job $(n=7,570)$ and lose job $(n=129,836) .{ }^{\ddagger}$ Results adjusted for donors' sex, age, educational level and the total number of previous blood donations. ${ }^{\S}$ Estimated unstandardized regression coefficients. $I I$ OR indicates the likelihood for donor lapse compared with the reference category. "Percentage reported only when all paths in the model were significant. ${ }^{16}$

$* * * p<.001 * * p<.01 * p<.05$ (two-tailed tests) 
Table 3. Results for the stepwise regression analyses ${ }^{*}$ of the health-related life events on donor lapse ${ }^{\dagger}$

\begin{tabular}{|c|c|c|c|c|c|c|c|c|c|c|c|c|c|c|}
\hline \multirow[b]{2}{*}{ Life events ${ }^{\ddagger}$} & \multicolumn{2}{|c|}{ Model 1} & \multicolumn{2}{|c|}{ Model 2} & \multicolumn{2}{|c|}{ Model 3} & \multicolumn{2}{|c|}{ Model 4} & \multicolumn{2}{|c|}{ Model 5} & \multicolumn{2}{|c|}{ Model 6} & \multicolumn{2}{|c|}{ Model 7} \\
\hline & $\mathrm{B}^{\S}$ & SE & B & SE & B & SE & B & SE & B & SE & B & SE & B & SE \\
\hline Transfusion & $-.097 * * *$ & .012 & & & & & $-.047 *$ & .019 & $-.044 *$ & .019 & & & -.018 & \\
\hline Serious disease & & & $-.128 * * *$ & .012 & & & $-.115^{* * *}$ & .013 & & & $-.097 * * *$ & .013 & $-.095^{* * *}$ & .014 \\
\hline Death & & & & & $-.171 * * *$ & .019 & & & $-.155^{* * *}$ & .020 & $-.120 * * *$ & .019 & $-.115^{* * *}$ & .021 \\
\hline
\end{tabular}

${ }^{*}$ Effects are estimated separately for each health-related life event in Models 1-3, in combination with one of the other health-related life events in Models 4-6, simultaneously for al three health-related life events in Model 7 , and only when the donor is at risk for experiencing the event $(n=152,887) .{ }^{\dagger}$ Blood donor lapse for non-medical reasons. ${ }^{\ddagger}$ Results adjusted for donors' sex, age, educational level and the total number of previous blood donations. ${ }^{\S}$ Estimated unstandardized regression coefficients.

$* * * p<.001 * * p<.01 * p<.05$ (two-tailed tests) 


\section{APPENDIX A}

\section{COMPARISON OF DUTCH AND DANISH VARIABLES}

Table 1. Overview of the variables used in the original Dutch study and the corresponding variables used in the current Danish replication study

\begin{tabular}{|c|c|c|c|c|c|c|}
\hline Variable & $\begin{array}{l}\text { THE NETHERLANDS } \\
\text { Coding }\end{array}$ & Note & Data* & $\begin{array}{l}\text { DENMARK } \\
\text { Coding }\end{array}$ & Note $^{+}$ & Data* \\
\hline Blood donor lapse & $\begin{array}{l}0=\text { donation } 24 \text { months after DIS-II } \\
1=\text { no donation } 24 \text { months after DIS-II }\end{array}$ & - & eProgesa & $\begin{array}{l}0=\text { donation in } 2013-2014 \\
1=\text { no donation in } 2013-2014\end{array}$ & - & SCANDAT \\
\hline Transfusion & $\begin{array}{l}0=\text { no transfusion DIS-I }- \text { DIS-II } \\
1=\text { transfusion DIS-I }- \text { DIS-II }\end{array}$ & $\begin{array}{l}\text { Transfusion for parents, siblings or } \\
\text { children }\end{array}$ & DIS-I \& -II & $\begin{array}{l}0=\text { no transfusion } 2009-2012 \\
1=\text { transfusion } 2009-2012\end{array}$ & - & SCANDAT \\
\hline Serious disease & $\begin{array}{l}0=\text { no disease DIS-I - DIS-II } \\
1=\text { disease DIS-I - DIS-II }\end{array}$ & $\begin{array}{l}\text { Cancer, stroke or heart attack for } \\
\text { parents, siblings or children }\end{array}$ & DIS-I \& -II & $\begin{array}{l}0=\text { no serious disease } 2009-2012 \\
1=\text { serious disease } 2009-2012\end{array}$ & - & LPRDIAG \\
\hline Death & $\begin{array}{l}0=\text { no death DIS-I }- \text { DIS-II } \\
1=\text { death DIS-I }- \text { DIS-II }\end{array}$ & $\begin{array}{l}\text { Death of parents, siblings or } \\
\text { children }\end{array}$ & DIS-I \& -II & $\begin{array}{l}0=\text { no death } 2009-2012 \\
1=\text { death } 2009-2012\end{array}$ & - & DODSAARS \\
\hline Childbirth & $\begin{array}{l}0=\text { no childbirth DIS-I - DIS-II } \\
1=\text { childbirth DIS-I - DIS-II }\end{array}$ & $\begin{array}{l}\text { Men aged } 55 \text { and younger and } \\
\text { women aged } 45 \text { and younger were } \\
\text { included }\end{array}$ & DIS-I \& -II & $\begin{array}{l}0=\text { no childbirth } 2009-2012 \\
1=\text { childbirth } 2009-2012\end{array}$ & - & FAM \\
\hline Starting a job & $\begin{array}{l}0=\text { unemployed DIS-I - DIS-II } \\
1=\text { started job DIS-I }- \text { DIS-II }\end{array}$ & $\begin{array}{l}\text { Donors who were unemployed at } \\
\text { time of DIS-I were included }\end{array}$ & DIS-I \& -II & $\begin{array}{l}0=\text { unemployed } 2009-2012 \\
1=\text { started job } 2009-2012\end{array}$ & - & IDAP \\
\hline Losing a job & $\begin{array}{l}0=\text { employed DIS-I - DIS-II } \\
1=\text { lost job DIS-I - DIS-II }\end{array}$ & $\begin{array}{l}\text { Donors who had a job at the time } \\
\text { of DIS-I were included }\end{array}$ & DIS-I \& -II & $\begin{array}{l}0=\text { employed } 2009-2012 \\
1=\text { lost job } 2009-2012\end{array}$ & - & IDAP \\
\hline Working hours & $x=$ working hours per week & - & DIS-II & $x=$ working hours per week & - & AKM \\
\hline Know other donors & $\begin{array}{l}0=\text { does not know other donors } \\
1=\text { knows other donors }\end{array}$ & $\begin{array}{l}\text { Survey options: friends, family, } \\
\text { acquaintances }\end{array}$ & DIS-II & $\begin{array}{l}0=\text { no other donors in the family } \\
1=\text { other donors in the family }\end{array}$ & $\begin{array}{l}\text { Only the donors in the family, } \\
\text { not acquaintances, could be } \\
\text { identified (i.e., spouse, child, } \\
\text { sibling, parent) }\end{array}$ & SCANDAT \\
\hline Age & $\mathrm{x}=\mathrm{age}$ & - & eProgesa & $x=$ age & - & BEF \\
\hline Female & $\begin{array}{l}0=\text { male } \\
1=\text { female }\end{array}$ & - & eProgesa & $\begin{array}{l}0=\text { male } \\
1=\text { female }\end{array}$ & - & BEF \\
\hline Educational level & $\begin{array}{l}1=\text { low } \\
2=\text { middle } \\
3=\text { high }\end{array}$ & $\begin{array}{l}1 \text { = none, prevocational secondary, } \\
\text { lower general secondary } \\
2 \text { = senior secondary vocational, } \\
\text { senior general secondary, pre- } \\
\text { university }\end{array}$ & DIS-I & $\begin{array}{l}1=\text { low } \\
2=\text { middle } \\
3=\text { high }\end{array}$ & $\begin{array}{l}\text { Not the same in DK, but the } \\
\text { categories are based on the } \\
\text { ISCED2011 } 1^{\ddagger} \text { to make the same } \\
\text { categories as in Dutch data }\end{array}$ & UDDA \\
\hline
\end{tabular}




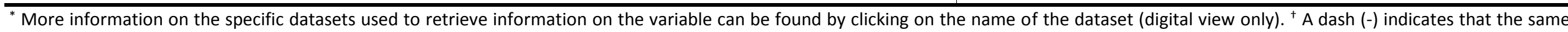

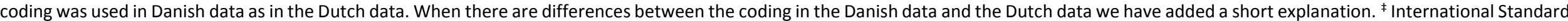

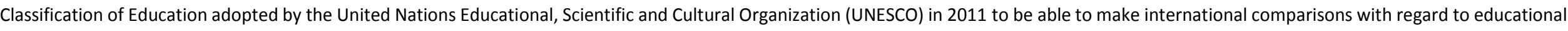
systems. ${ }^{\S}$ 
APPENDIX B

\section{RESULTS FROM THE NETHERLANDS}

Table 1. Descriptive statistics of study measures, for the total blood donor sample in the Netherlands and stratified by donor status ${ }^{*},+$

\begin{tabular}{lrrr}
\hline Characteristic & $\begin{array}{r}\text { All donors } \\
(\mathrm{n}=20,560)\end{array}$ & $\begin{array}{r}\text { Active donors } \\
(\mathrm{n}=15,363 ; 74.7 \%)\end{array}$ & $\begin{array}{r}\text { Lapsed donors } \\
(\mathrm{n}=5,197 ; 25.3 \%)\end{array}$ \\
\hline Life events & $1,855(9.0 \%)$ & $1,425(9.3 \%)$ & $430(8.3 \%)$ \\
$\quad$ Transfusion & $8,319(40.5 \%)$ & $6,206(40.4 \%)$ & $2,113(40.7 \%)$ \\
$\quad$ Serious disease & $3,884(18.9 \%)$ & $2,966(19.3 \%)$ & $918(17.7 \%)$ \\
$\quad$ Death & $2,071(10.1 \%)$ & $1,268(8.3 \%)$ & $803(15.5 \%)$ \\
$\quad$ Childbirth & $469(2.3 \%)$ & $343(2.2 \%)$ & $126(2.4 \%)$ \\
$\quad$ Starting a job & $622(3.0 \%)$ & $447(2.9 \%)$ & $175(3.4 \%)$ \\
$\quad$ Losing a job & & & $22.5( \pm 17.3)$ \\
Costs & $25.6( \pm 16.7)$ & $26.7( \pm 16.4)$ & \\
$\quad$ Working hours & & & $3,575(68.8 \%)$ \\
Social network & $15,056(73.2 \%)$ & $11,481(74.7 \%)$ & $46.9( \pm 14.61)$ \\
$\quad$ Know other donors & $46.7( \pm 12.28)$ & $46.7( \pm 11.38)$ & $2,100(40.5 \%)$ \\
Age & & & $3,097(59.6 \%)$ \\
Sex & $9,706(47.2 \%)$ & $7,606(49.5 \%)$ & $154(3.0 \%)$ \\
$\quad$ Male & $10,854(52.8 \%)$ & $7,757(50.5 \%)$ & $2,966(57.1 \%)$ \\
$\quad$ Female & $517(2.5 \%)$ & $363(2.4 \%)$ & $2,059(39.6 \%)$ \\
Educational level & $12,479(60.7 \%)$ & $9,513(61.9 \%)$ & $16(8-31)$ \\
$\quad$ Low & $7,476(36.4 \%)$ & $5,417(35.3 \%)$ & $23(11-39)$ \\
$\quad$ Middle & $21(10-37)$ & & \\
High & Previous blood donations & & \\
\hline
\end{tabular}

${ }^{*}$ Data reported as mean $( \pm \mathrm{SD})$, number $(\%)$, or median $\left(25^{\text {th }}-75^{\text {th }}\right) .{ }^{\dagger}$ Adapted from the study by Piersma and colleagues. ${ }^{2}$ 
Table 2. Results for the logistic regression analyses of life events on blood donor lapse in the Netherlands ${ }^{*}{ }^{\dagger}$ mediated by the hypothesized mechanisms ${ }^{\ddagger}$

\begin{tabular}{|c|c|c|c|c|c|c|c|c|}
\hline \multirow[b]{2}{*}{ Life events \& mechanisms ${ }^{\S}$} & \multicolumn{3}{|c|}{ Model A } & \multicolumn{3}{|c|}{ Model B } & \multicolumn{2}{|c|}{$Z_{\text {Mediation }}$} \\
\hline & $\mathrm{B}^{\mathrm{II}}$ & SE & OR" $(95 \% \mathrm{Cl})$ & $B$ & SE & OR $(95 \% \mathrm{Cl})$ & $\%$ mediated $^{* *}$ & Z-value \\
\hline Transfusion & $-0.13 *$ & 0.06 & $0.87(0.78-0.98)$ & $-0.14^{*}$ & 0.06 & $0.87(0.79-0.98)$ & & \\
\hline Know other donors & & & & $-0.28 * * *$ & 0.04 & $0.76(0.70-0.81)$ & - & 1.33 \\
\hline Serious disease & 0.02 & 0.03 & $1.02(0.95-1.09)$ & & & & & \\
\hline Death & $-0.11 *$ & 0.04 & $0.90(0.83-0.98)$ & $-0.12 *$ & 0.04 & $0.89(0.82-0.97)$ & & \\
\hline Know other donors & & & & $-0.27 * * *$ & 0.04 & $0.77(0.71-0.83)$ & - & 0.15 \\
\hline Childbirth & $0.60^{* * *}$ & 0.06 & $1.83(1.63-2.00)$ & $0.49 * * *$ & 0.06 & $1.64(1.46-1.84)$ & & \\
\hline Start job & $0.30^{* * *}$ & 0.15 & $1.34(1.02-1.77)$ & 0.12 & 0.23 & $1.08(0.77-1.38)$ & & \\
\hline Lose job & $0.40^{* * *}$ & 0.09 & $1.50(1.25-1.80)$ & $0.39 * * *$ & 0.10 & $1.48(1.48-1.23)$ & & \\
\hline Know other donors & & & & $-0.27 * * *$ & 0.05 & $0.76(0.70-0.84)$ & $3 \%$ & $2.68 * *$ \\
\hline
\end{tabular}

${ }^{*}$ Blood donor lapse for non-medical reasons. ${ }^{\dagger}$ Adapted from the study by Piersma and colleagues. ${ }^{2}{ }^{\ddagger}$ Effects are estimated separately for each life event and its hypothesized mechanisms, and only when the donor is at risk for experiencing the life event: transfusion, disease and death $(n=20,560)$, childbirth $(n=11,695)$, start job ( $n=1,713)$ and lose job $(n=15,356) .{ }^{\S}$ Results adjusted for donors' sex, age, educational level, religious affiliation and the total number of previous blood donations. 11 Estimated unstandardized regression coefficients. "OR indicates the likelihood for donor lapse compared with the reference category. ${ }^{* *}$ Percentage reported only when all paths in the model were significant. ${ }^{16}$

$* * * p<.001 * * p<.01 * p<.05$ (two-tailed tests) 


\section{APPENDIX C \\ CORRELATION MATRIX}

Table 1. Correlation matrix including Spearman correlations $(r)$ between all study measures

\begin{tabular}{|c|c|c|c|c|c|c|c|c|c|c|c|c|c|}
\hline Measure* & 1 & 2 & 3 & 4 & 5 & 6 & 7 & 8 & 9 & 10 & 11 & 12 & 13 \\
\hline 1. Blood donor lapse & - & & & & & & & & & & & & \\
\hline 2. Transfusion & $-.02 * * *$ & - & & & & & & & & & & & \\
\hline 3. Serious disease & $-.03^{* * *}$ & $.30 * * *$ & - & & & & & & & & & & \\
\hline 4. Death & $-.03 * * *$ & $.35 * * *$ & $.35^{* * *}$ & - & & & & & & & & & \\
\hline 5. Childbirth & $.04 * * *$ & $-.02 * * *$ & $-.01^{* * *}$ & $-.05^{* * *}$ & - & & & & & & & & \\
\hline 6. Starting a job & -.01 & -.01 & -.01 & -.00 & $.08^{* * *}$ & - & & & & & & & \\
\hline 7. Losing a job & $.05^{* * *}$ & $-.02 * * *$ & $-.02^{* * *}$ & $-.02^{* * *}$ & -.00 & .00 & - & & & & & & \\
\hline 8. Working hours & $-.08 * * *$ & $.04^{* * *}$ & $.07^{* * *}$ & $.05^{* * *}$ & $.03^{* * *}$ & $.29 * * *$ & $-.28^{* * *}$ & - & & & & & \\
\hline 9. Know other donors & $-.08^{* * *}$ & -.00 & .00 & $-.01 * *$ & $.04^{* * *}$ & $.05^{* * *}$ & -.00 & $.44^{* * *}$ & - & & & & \\
\hline 10. Age & $-.03 * * *$ & $.04 * * *$ & $-.01 * * *$ & $.09 * * *$ & $-.33^{* * *}$ & -.00 & $-.15^{* * *}$ & $.07^{* * *}$ & $.03^{* * *}$ & - & & & \\
\hline 11. Sex & $.07^{* * *}$ & $-.01 *$ & $-.01 *$ & $-.02 * * *$ & -.00 & .02 & $.03^{* * *}$ & $.02 * * *$ & $.01 *$ & $-.09 * * *$ & - & & \\
\hline 12. Education & $-.03 * * *$ & .00 & $.03^{* * *}$ & .00 & $.12^{* * *}$ & $.18^{* * *}$ & $-.11^{* * *}$ & $.18^{* * *}$ & -.00 & $.03^{* * *}$ & $.04^{* * *}$ & - & \\
\hline 13. Previous donations & $-.12 * * *$ & $.03 * * *$ & $.03 * * *$ & $.06 * * *$ & $-.09 * * *$ & $.06 * * *$ & $-.11^{* * *}$ & $-.12 * * *$ & $-.13^{* * *}$ & $.04 * * *$ & $.07 * * *$ & $.07 * * *$ & - \\
\hline
\end{tabular}

${ }^{*}$ Measures ordered by category: blood donor lapse (1), life events (2-7), mechanisms (8-9), and control variables (10-13)

$* * * p<.001 * * p<.01 * p<.05$ (two-tailed tests) 